\title{
O USO DA MADEIRA NAS REDUÇÕES JESUÍTICO-GUARANI DO RIO GRANDE DO SUL. 10 - IMAGEM DE SANTO ESTANISLAU KOSTKA ${ }^{1}$
}

\author{
JOSÉ NEWTON CARDOSO MARCHIORI² MARIA CRISTINA SCHULZE-HOFER ${ }^{3}$
}

\section{RESUMO}

A madeira da imagem de Santo Estanislau Kostka, integrante do Museu das Missões, foi anatomicamente identificada como Cedrela fissilis Vellozo (Meliaceae), espécie botânica conhecida regionalmente como "cedro" no sul do Brasil.

Palavras-chave: Anatomia da madeira, Cedrela fissilis, cedro, Missões Jesuíticas, Rio Grande do Sul, Santo Estanislau Kostka.

\section{SUMMARY}

[Wood utilization in the Jesuitic-Guarani Missions from Rio Grande do Sul state, Brazil. 10 - The sculpture of Saint Stanislaw Kostka].

The sculpture wood of Saint Stanislaw Kostka, housed at Missions Museum (São Miguel das Missões, Rio Grande do Sul, Brazil), was anatomically identified as Cedrela fissilis Vellozo (Meliaceae), the Spanish cedar of southern Brazil.

Key words: Wood anatomy, Cedrela fissilis, Spanish cedar, Jesuitic Missions, Rio Grande do Sul state, Saint Estanislau Kostka.

\section{INTRODUÇÃO}

Catalogada, inicialmente, como São Luiz Gonzaga, a imagem de Santo Estanislau Kostka é de autoria desconhecida e data, provavelmente, do século XVIII. Conservada no Museu das Missões (São Miguel das Missões, RS), foi esculpida em bloco único de madeira (170 x $58 \mathrm{x}$ $37 \mathrm{~cm}$ ), apresenta sinais do ataque de insetos xilófagos e foi restaurada em 1985. Representa uma figura masculina jovem e sorridente, em pé, com rosto de fisionomia européia, levemente inclinada para a direita, de cabelos curtos, com batina preta e mão direita ao peito (Figura 1A). O panejamento e traços do rosto denotam erudição. Falta parte do nariz, o braço esquer-

Recebido em 25-VI-2009 e aceito para publicação em 21-II-2010.

${ }^{2}$ Engenheiro Florestal, Dr., bolsista de Produtividade em Pesquisa ( $\mathrm{CNPq}$ - Brasil), Professor Titular do Departamento de Ciências Florestais, Universidade Federal de Santa Maria, Santa Maria, RS. balduinia@mail.ufsm.br

${ }^{3}$ Arquiteta, Dra. IPHAN - Instituto do Patrimônio Histórico e Artístico Nacional. schulze-hofer@gmx.de do, os dedos da mão direita, o sapato direito e parte da veste, na manga (Figura 1A).

\section{MATERIAL E MÉTODOS}

O material estudado consiste de uma amostra de madeira (Figura 1B, C), retirada da parte posterior da imagem em julho de 2005, pelo restaurador Ariston Correia Filho.

A amostra foi registrada em fichário, fotografada, acondicionada em envelope com identificação e enviada ao Laboratório de Anatomia da Madeira, do Instituto Nacional de Pesquisas da Madeira, em Lohbrügge (Hamburgo - Alemanha), onde foram realizados os trabalhos de microtécnica e fotomicrografia. Os autores agradecem a Sra. Eda John, pela colaboração prestada nestas tarefas.

$\mathrm{Da}$ amostra de madeira foram preparados corpos-de-prova orientados para a obtenção de cortes nos três planos anatômicos. Os corposde-prova foram amolecidos por fervura em água e seccionados em micrótomo de deslizamento, regulado na espessura nominal de $20 \mu \mathrm{m}$. Os cortes anatômicos não sofreram coloração; no 


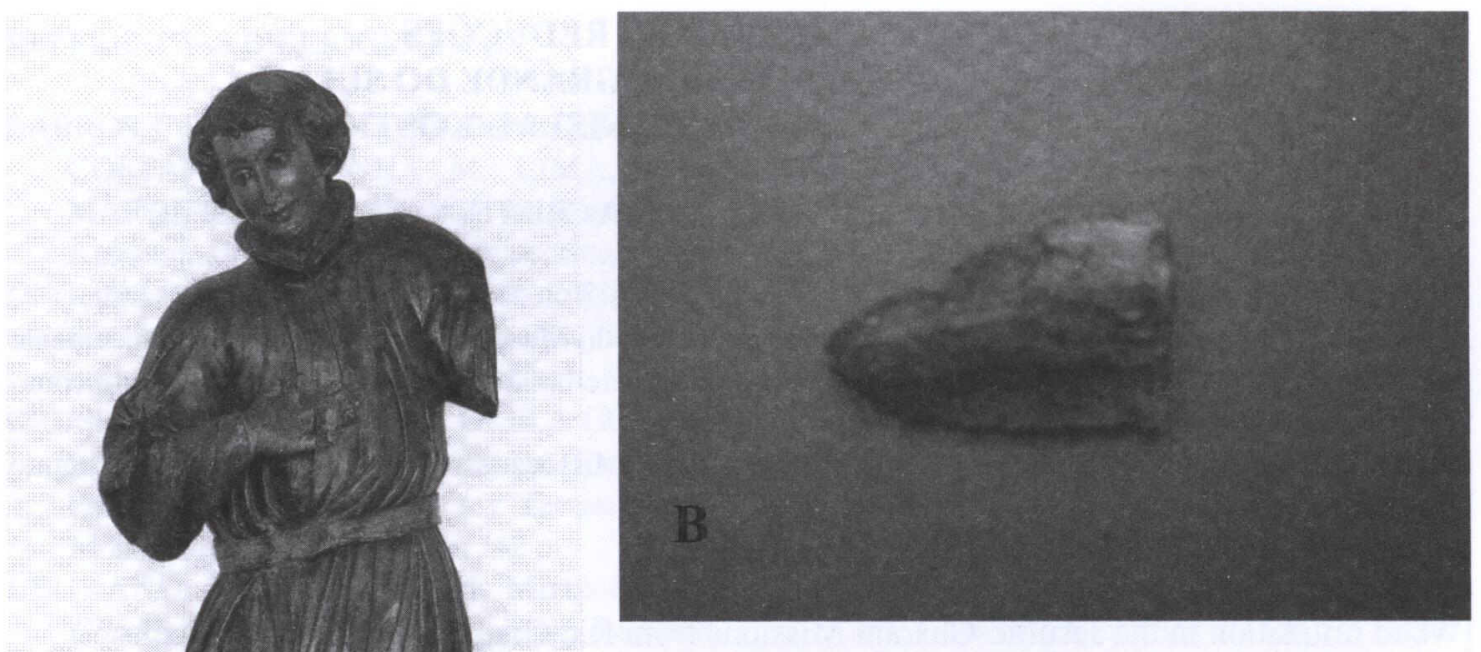

A

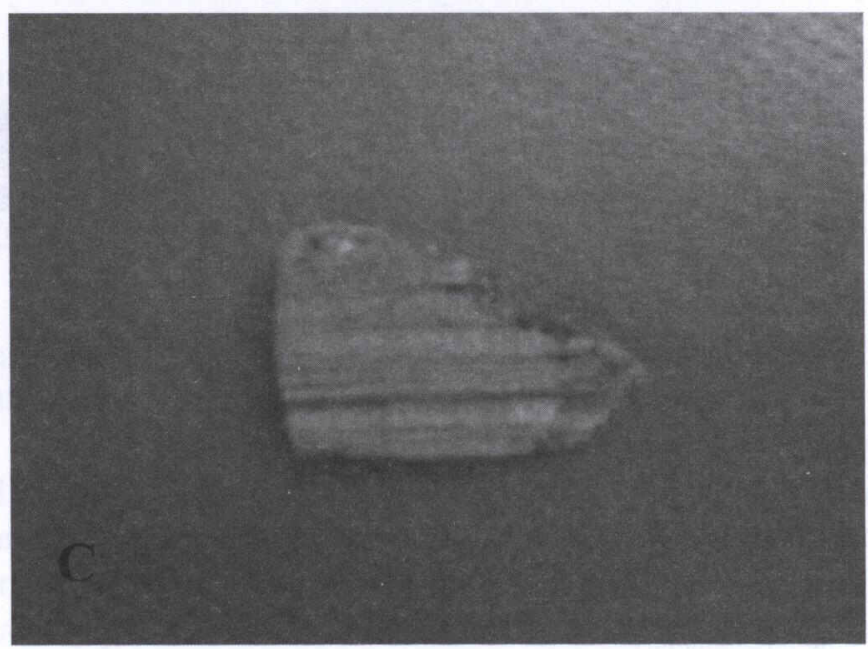

FIGURA 1 - Santo Estanislau Kostka. A - Fotografia da imagem missioneira. B, C - Frente e verso da amostra de madeira coletada.

caso dos radiais, parte deles foi tratado com hipoclorito de sódio, com vistas a salientar a visualização de eventuais estruturas cristalinas nas células lenhosas. As fotomicrografias da Figura 2 foram tomadas com câmera Olympus $\mathrm{AX}$, com diferentes aumentos.

\section{DESCRIÇÃO ANATÔMICA}

Madeira porosa, de Angiospermae Dicotyledoneae ou Magnoliophyta (Figura 2A, B). Anéis de crescimento demarcados por faixa de parênquima marginal. Porosidade difusa (Figura 2A).

Vasos pouco numerosos $(5-8 / \mathrm{mm})$, circulares ou ovais, de diâmetro pequeno a grande $(60-300 \mu \mathrm{m})$, com abundante óleo-resina e geralmente solitários, menos comumente geminados ou em múltiplos de poucas unidades (Figura 2A, B). Elementos vasculares retilíneos, com placas de perfuração simples, horizontais ou ligeiramente oblíquas. Pontoações intervasculares alternas, poligonais, 

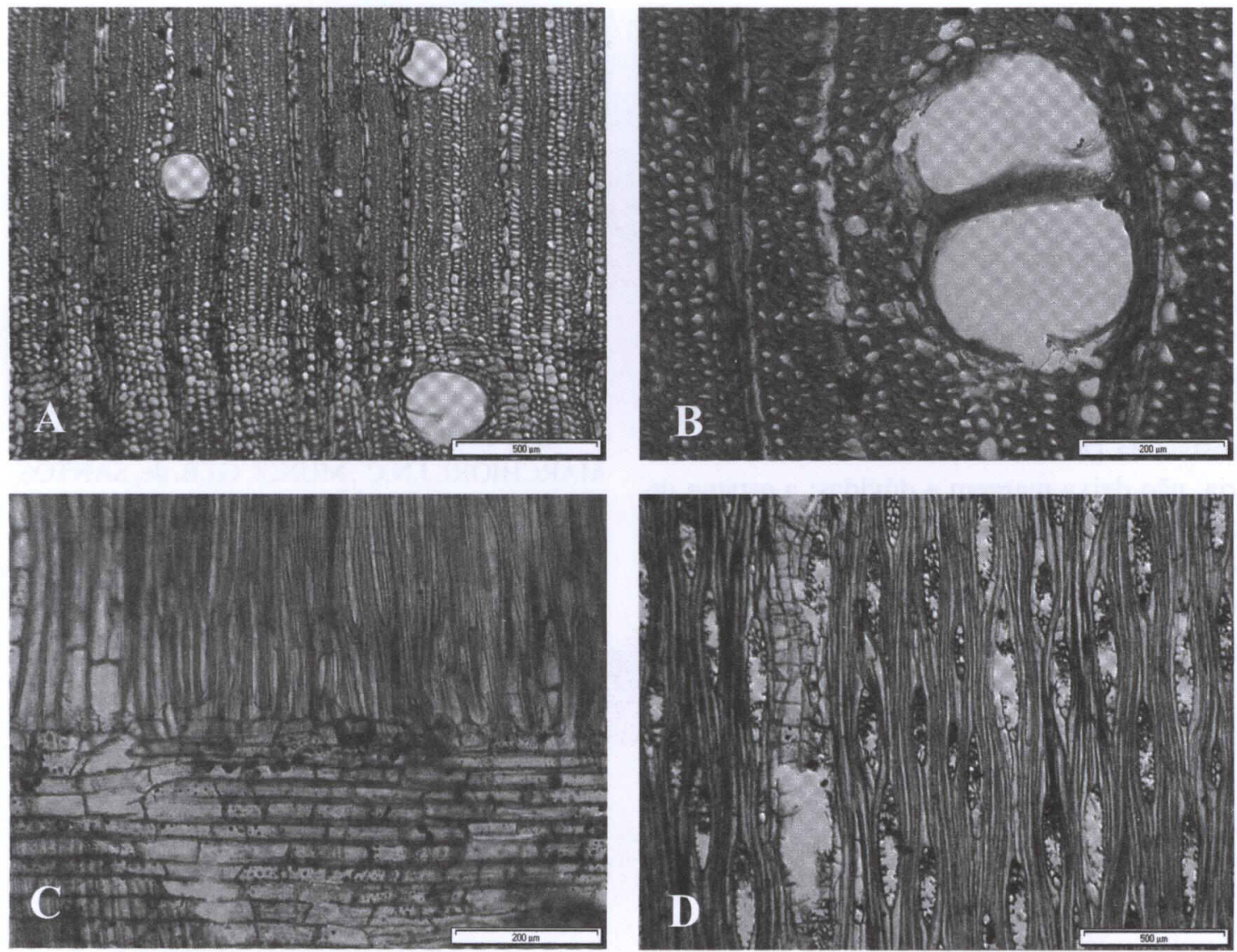

FIGURA 2 - Fotomicrografias da madeira da imagem de Santo Estanislau Kostka. A - Porosidade difusa, poros pouco numerosos e solitários (seção transversal). B - Poros geminados, raios finos e fibras de paredes finas (seção transversal). C - Raios heterogêneos, de células procumbentes, com células mais altas na margem (seção longitudinal radial). D Fibras de paredes finas e raios predominantemente bi a tetrasseriados, com menos de 25 células de altura (seção longitudinal tangencial).

de 5-10 4 m de diâmetro, com abertura elíptica inclusa, por vezes coalescente.

Parênquima apotraqueal marginal, em faixas regulares de 1 - 7 células de largura, além de apotraqueal difuso e paratraqueal escasso. Séries parenquimáticas axiais de $2-6$ células ( $\mathrm{Fi}$ gura $2 \mathrm{C}$ ), com abundante óleo-resina e, por vezes, cristais rombóides de oxalato de cálcio.

Raios pouco numerosos ( $4-7 / \mathrm{mm})$, muito baixos até baixos (menos de 25 células de altura) e predominantemente bi a tetrasseriados, com escassos uni e multisseriados (Figura 2D). Estrutura radial homogênea até heterogênea, reunindo células procumbentes, no centro, e uma fileira de células quadradas, na margem
(Figura 2C).

Tecido fibroso proeminente, composto de fibras libriformes curtas a longas, estreitas a médias e de paredes muito delgadas a delgadas (Figura 2B - D).

\section{ANÁLISE DA ESTRUTURA ANATÔMICA}

A madeira é de fácil identificação, com base em chave dicotômica para madeiras argentinas (Tortorelli, 1956): lenho fundamentalmente vascular; madeira sem estrutura estratificada; vasos com pontoações simples e pontoações alternas; canais intercelulares ausentes; poros com frequiência inferior a $45 / \mathrm{mm}^{2}$, em disposição não dendrítica ou ulmiforme; raios lenhosos bi a 
multisseriados, com escassos unisseriados e sempre com menos de $1 \mathrm{~mm}$ de altura; parênquima predominantemente apotraqueal marginal; poros pouco numerosos; e fibras com lúmen de $1 / 2$ a $3 / 4$ do diâmetro total.

A comparação dos detalhes anatômicos acima relacionados com descrições de Cedrela fissilis (Mainieri \& Chimelo, 1989; Marchiori et al., 2009; Tortorelli, 1956), bem como com amostras da referida espécie, representadas no Laminário do Departamento de Ciências Florestais da Universidade Federal de Santa Maria, não deixa margem a dúvidas: a estátua de Santo Estanislau Kostka foi realizada em madeira de cedro - Cedrela fissilis Vellozo (Meliaceae) -, espécie também conhecida, popularmente, como cedro-vermelho.
A respeito da espécie botânica, cabe salientar que não existe na flora regional madeira mais dócil para esculturas e obras de talha, aliada à boa durabilidade natural e acabamento. De odor agradável, esta madeira também aceita muito bem a aplicação de pigmentos, aspecto importante em obras religiosas (policromia).

\section{REFERÊNCIAS BIBLIOGRÁFICAS}

MAINIERI, C.; CHIMELO, J.P. Fichas de características das madeiras brasileiras. São Paulo: IPT, 1979. $418 \mathrm{p}$.

MARCHIORI, J.N.C.; MUÑIZ, G.I.B. de; SANTOS, S.R. dos. Madeiras do Rio Grande do Sul. 1 Descrição microscópica de 33 espécies nativas. Santa Maria: [s.n.], 2009. 80 p.

TORTORELLI, L.A. Maderas y bosques argentinos. Buenos Aires: ACME, 1956. 910 p. 